\title{
Ni-Al Functionally Graded Materials by Laser Self-Propagating High-Temperature Synthesis
}

\author{
Chen Lei ${ }^{1}$, Hu Jiandong ${ }^{2}$, Guo Zuoxing ${ }^{2}$, Lou Qihong ${ }^{1}$ and Wang Zhijiang ${ }^{1}$ \\ ${ }^{1}$ Shanghai Institute of Optics and Fine Mechanics, Shanghai 201800, P.R. China \\ ${ }^{2}$ Jilin University, Jilin 130025, P.R. China
}

\begin{abstract}
In recent years, functionally gradient materials have been developed. But we seldom see the paper about that FGMs are produced by making use of laser. In this paper, we make FGMs with laser in self-propagating high-temperature synthesis. We select nickel and aluminum powders, which can react and release much heat. The ignition time and reaction time are shortened. And the highest temperature which reaction can get is improved. Utilizing the laser of high power density, we can get more complete product. And the composite process of phase in this method is different from that in tradition method.
\end{abstract}

(Received December 11, 2003; Accepted June 8, 2004)

Keywords: laser, self-propagating high-temperature synthesis, functionally gradient materials, sintering

\section{Introduction}

Functionally graded materials (FGMs) are materials in which certain properties change continuously from one surface to the other. The preparation of FGMs has been performed by a number of techniques, related to both ceramics and metal processing which have been widely discussed in the international meetings on this subject, and summarized in some papers. ${ }^{1,2}$

The methods so far used to produce FGMs have included chemical and physical vapor deposition, ${ }^{3)}$ powder metallurgy, ${ }^{4)}$ plasma spray and self-propagating high-temperature synthesis (SHS). ${ }^{5)}$ All these methods have some drawbacks. In these methods, SHS is increasingly used owing to the lower cost and better availability of starting materials, simple processing equipment, and lower energy consumption resulting from less heat input and shorter processing times and higher product purity because of less reaction during the processing. ${ }^{2)}$ SHS is a general processing technique in which reactants, usually elemental constituents, when are ignited, spontaneously transform to products as a result of the exothermic heat of formation. The steps involved in SHS are reactant powders preparation, cold compaction and occur either as a wave propagating across the specimen from a single ignition source or as volumetric combustion where the reaction is ignited at multiple sites throughout the specimen as a result of uniform heating of the entire specimen. The combustion wave velocity and stability control the level of porosity and uniformity of the product phase. The combustion wave can be controlled by the heating rate, reactant particle size, shape and distribution, specimen green density and diameter, conductive cooling, the addition of pretreated diluents and externally applied pressure.

SHS composites are formed either by mechanically adding the reinforcement to the reactant powder mixtures, when the product consists of two or more materials formed from the reactants. In the former, chemical interaction may occur between the reactants and the reinforcement, whereas the latter would produce a composite with matrix and reinforcement in a state of thermodynamic equilibrium. ${ }^{3)}$ Long-term elevated temperature stability requires such a state of equilibrium or the development of a diffusion barrier at the matrix-reinforcement interface to provide a "kinetic equilibrium" to eliminate matrix-reinforcement interaction. This is important, in part because the contribution of the interface has a great influence on the mechanical behavior of the whole materials. High-power laser, such as the $\mathrm{CO}_{2}$ type, is already used in coating technology by making use of its advantageous features, namely a clean source of energy, high local heat input, non-contact heating, and rapid and flexible processing which is amenable to computer control. Jasim et al. ${ }^{6)}$ has used a laser to produce a clad layer on variable compositions as a function of distance along the surface of a substrate.

With the development of science and technology, FGMs have been used from originally space navigation to nuclear energy, electron, optics, chemistry, and biomedicine etc. regions. At present FGMs include metal and ceramics, metalalloy, nonmetal and nonmetal, nonmetal and ceramics. And they have a wide applied future.

\section{Experiment}

The powders used for experiments were nickel and aluminium with a size of range from -200 to 200 mesh. The compositions of the powder mixtures are listed in Table 1. The powders for every layer were weighed and mixed in a ceramic bowl. After the homogeneity was confirmed by hand, put them orderly into the mould and pressed the mixed powder into two different green compact. The first green compact was pressed in a cylinder die, with diameter of $13 \mathrm{~mm}$. The second green compact was pressed in a rectangle die with $65 \mathrm{~mm} \times 10 \mathrm{~mm} \times 4 \mathrm{~mm}$, the compositions are same as the sample 3 in Table 1.

The SHS processing are shown in Fig. 1. A laser irradiates from the surface of a green compact. When the reaction temperature of nickel and aluminium is got, we turn down the laser. Then the following reaction depends on chemical heat, which is produced by the reaction between nickel and aluminium. We get the FGMs after SHS is finished.

To compare the density of the sintered samples, we introduce densification parameter $\phi$. 
Table 1 Composition of Ni-Al composites studied in this work (wt\%).

\begin{tabular}{|c|c|c|c|c|c|c|}
\hline Layer & 1 & 2 & 3 & 4 & 5 & 6 \\
\hline First layer & $\mathrm{Ni}$ & $\mathrm{Ni}$ & $\mathrm{Ni}$ & $\mathrm{Ni}$ & $\mathrm{Ni}$ & $\mathrm{Ni}$ \\
\hline Second layer & $\mathrm{Ni}-5 \mathrm{Al}$ & $\mathrm{Ni}-10 \mathrm{Al}$ & $\mathrm{Ni}-20 \mathrm{Al}$ & $\mathrm{Ni}-10 \mathrm{Al}$ & $\mathrm{Ni}-20 \mathrm{Al}$ & $\mathrm{Ni}-5 \mathrm{Al}$ \\
\hline Third layer & $\mathrm{Ni}-10 \mathrm{Al}$ & $\mathrm{Ni}-30 \mathrm{Al}$ & $\mathrm{Ni}-40 \mathrm{Al}$ & $\mathrm{Ni}-20 \mathrm{Al}$ & $\mathrm{Ni}-30 \mathrm{Al}$ & $\mathrm{Ni}-10 \mathrm{Al}$ \\
\hline Fourth layer & $\mathrm{Ni}-15 \mathrm{Al}$ & $\mathrm{Ni}-50 \mathrm{Al}$ & $\mathrm{Ni}-60 \mathrm{Al}$ & $\mathrm{Ni}-30 \mathrm{Al}$ & $\mathrm{Ni}-50 \mathrm{Al}$ & $\mathrm{Ni}-20 \mathrm{Al}$ \\
\hline Fifth layer & $\mathrm{Ni}-20 \mathrm{Al}$ & $\mathrm{Ni}-70 \mathrm{Al}$ & $\mathrm{Ni}-80 \mathrm{Al}$ & - & $\mathrm{Ni}-60 \mathrm{Al}$ & $\mathrm{Ni}-25 \mathrm{Al}$ \\
\hline Sixth layer & $\mathrm{Ni}-25 \mathrm{Al}$ & $\mathrm{Ni}-90 \mathrm{Al}$ & $\mathrm{Al}$ & - & - & Ni-30Al \\
\hline Seventh layer & $\mathrm{Ni}-30 \mathrm{Al}$ & - & - & - & - & $\mathrm{Ni}-40 \mathrm{Al}$ \\
\hline Eighth layer & - & - & - & - & - & Ni-50Al \\
\hline Ninth layer & - & - & - & - & - & $\mathrm{Ni}-60 \mathrm{Al}$ \\
\hline Tenth layer & - & - & - & - & - & Ni-70Al \\
\hline Eleventh layer & - & - & - & - & - & $\mathrm{Ni}-80 \mathrm{Al}$ \\
\hline Twelfth layer & - & - & - & - & - & $\mathrm{Ni}-90 \mathrm{Al}$ \\
\hline
\end{tabular}

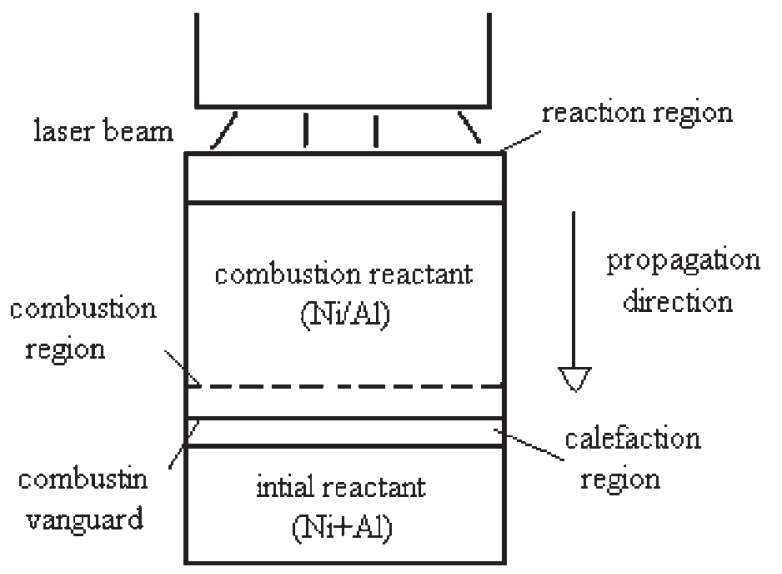

Fig. 1 Schematic representation of SHS.

$$
\phi=\frac{\rho_{\mathrm{s}}-\rho_{\mathrm{g}}}{\rho_{\mathrm{t}}-\rho_{\mathrm{g}}} \times 100 \%
$$

in this: $\rho_{\mathrm{t}}$-theoretical density $\left(6.0 \mathrm{~g} / \mathrm{cm}^{3}\right)$;

$\rho_{\mathrm{g}}$-green density $\left(\mathrm{g} / \mathrm{cm}^{3}\right)$;

$\rho_{\mathrm{s}}$-synthesized density $\left(\mathrm{g} / \mathrm{cm}^{3}\right)$.

\section{Experimental Results and Discussion}

\subsection{Sintering processing}

The sintered samples have some pores on the surfaces.

This is the ventholes of the combustion wave transmitting. After reaction is finished, gas is pushed forward and came out from the surface, so the pores come into being on the surface. Under the ignition temperature, the aluminium is melted (melt point is $993 \mathrm{~K}$ ) and liquid phase rapidly increases. It is difficult to control the process. So the top layers are concave, and the bottom layers are bulgy and rippled in sample 1, 2, 3 and 5. The sample 4 and 6 are integrated. There has a strange phenomenon. When the content of $\mathrm{Al}$ is $80 \%, 90 \%$, and $100 \%$ in the floor layer, a smarter reaction (judge from the lightness of flame) coming from bottom to top will happen. We think a hotter phase must have been produced; the quantity of heat given out by the hotter phase is enough to make another reaction from bottom to top.

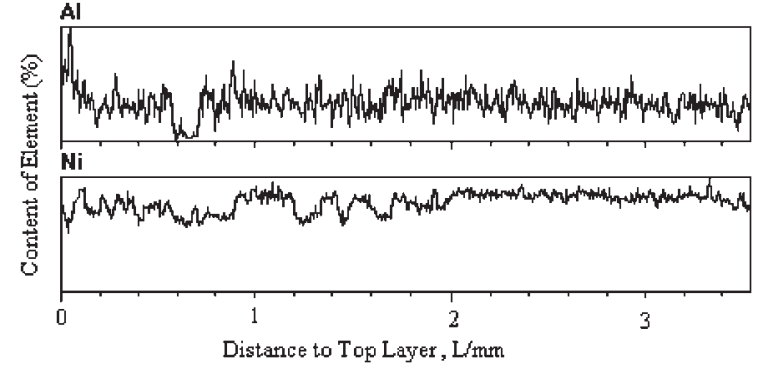

Fig. 2 The distribution of nickel and aluminium in FGMs after sinting.

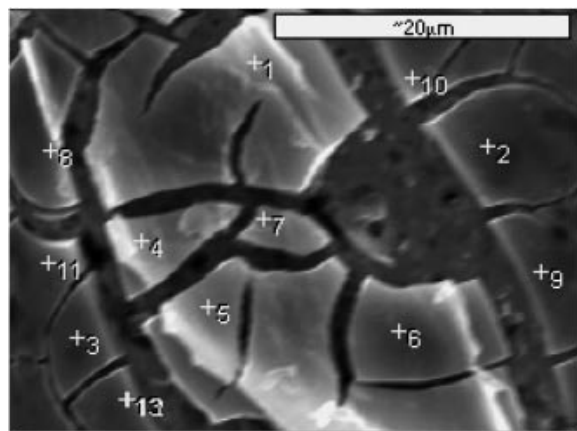

Fig. 3 The phase distributing in FGMs, point 1 is $\mathrm{Al}_{68.05} \mathrm{Ni}_{31.95}$, point 2 is $\mathrm{Al}_{21.00} \mathrm{Ni}_{79.00}$, point 3 is $\mathrm{Al}_{8.77} \mathrm{Ni}_{91.23}$, point 4 is $\mathrm{Al}_{48.28} \mathrm{Ni}_{51.72}$, point 5 is $\mathrm{Al}_{46.17} \mathrm{Ni}_{53.83}$, point 6 is $\mathrm{Al}_{5.27} \mathrm{Ni}_{94.73}$, point 7 is $\mathrm{Al}_{2.05} \mathrm{Ni}_{97.95}$, point 8 .

\subsection{Microstructure}

After the processing of SHS, the primitive gradient contribution was changed to continual contribution. Figure 2 shows the linear scanning of sintered FGMs. The distribution of nickel and aluminium elements is smooth in FGMs.

The contents in FGMs are different in any layer, so the transition layers must be the mixture of many phases. Figure 3 shows the phase distribution of transition layer between the second and three layer of sample 3. The laser-sintered specimens included many phase such as $\mathrm{Al}_{68.05} \mathrm{Ni}_{31.95}$, $\mathrm{Al}_{21.00} \mathrm{Ni}_{79.00}, \quad \mathrm{Al}_{8.77} \mathrm{Ni}_{91.23}, \quad \mathrm{Al}_{48.28} \mathrm{Ni}_{51.72}, \quad \mathrm{Al}_{46.17} \mathrm{Ni}_{53.83}$, $\mathrm{Al}_{5.27} \mathrm{Ni}_{94.73}, \quad \mathrm{Al}_{2.05} \mathrm{Ni}_{97.95}, \quad \mathrm{Al}_{19.75} \mathrm{Ni}_{80.25}, \quad \mathrm{Al}_{7.93} \mathrm{Ni}_{92.07}$, $\mathrm{Al}_{9.33} \mathrm{Ni}_{90.67}, \mathrm{Al}_{9.33} \mathrm{Ni}_{90.67}$ and $\mathrm{Al}_{9.33} \mathrm{Ni}_{90.67}$.

\subsection{Densification processing}

The $\rho_{\mathrm{s}}$ curve in Fig. 4 shows that the synthesis density will be enhanced with the increasement of green density. And the $\phi$ curve exhibits that the densification parameter decreases with the increasement of green density. It is easy to understand that the lower green density has higher densification parameter, but the synthesis density still be very low. However, the liquid phase difficultly flows in the samples of high green density. At the same time the grains distortion resulted from the press is harmful, so they are difficult to reset. On the other side, the residual gas makes the samples expand. So the higher green density has the lower densification parameter. Therefore we consider the green relative density is $70 \%$, the densification degree is the best. 


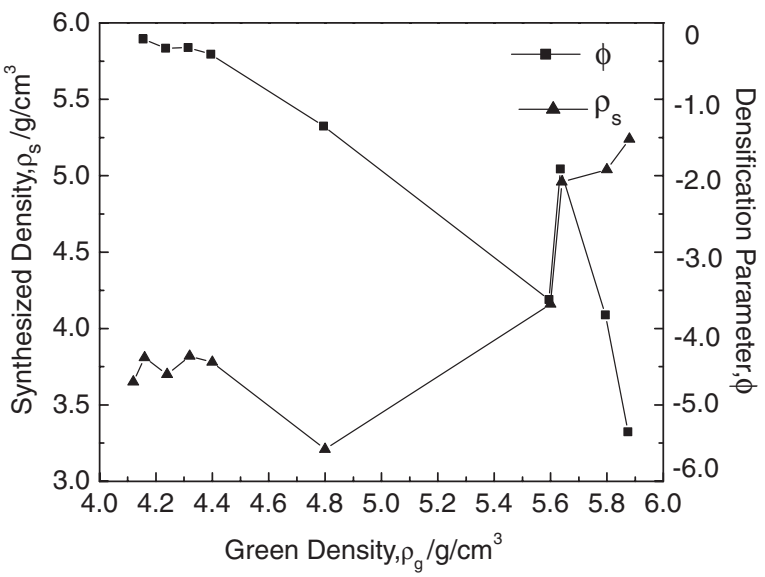

Fig. 4 Variation of densification parameter $(\phi)$ and synthesized density $\left(\rho_{\mathrm{s}}\right)$ with green density.

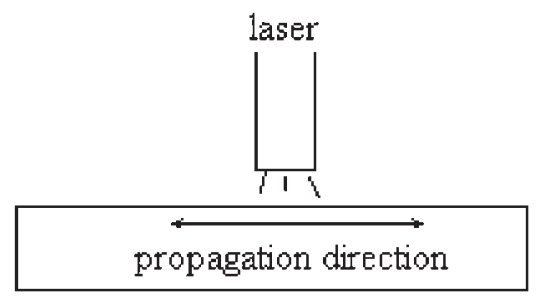

Fig. 5 Experiment sketch map.

\subsection{Phase production processing}

For conventional sintering, $\mathrm{NiAl}$ is get from $3 \mathrm{Al}+2 \mathrm{Ni}=$ $\mathrm{Ni}_{2} \mathrm{Al}_{3}, \mathrm{Ni}_{2} \mathrm{Al}_{3}+\mathrm{Al}=3 \mathrm{NiAl}{ }^{7,8)}$ The synthetic process of phase in FGMs produced by laser SHS aroses our interest. So we design the experiment (Fig. 5). The combustion wave transmits from ignition location (middle) to fringe position (edge). In ignition location $\mathrm{NiO}, \mathrm{NiAl}, \mathrm{Ni}$ and $\mathrm{NiAl}$ with rich $\mathrm{Ni}$ are majority. Moreover, $\mathrm{NiO}, \mathrm{Ni}_{3} \mathrm{Al}, \mathrm{Ni}$ and $\mathrm{NiAl}$ with rich $\mathrm{Ni}$ are main phases at fringe position (show Fig. 6). Nickel diffuses faster than aluminum in rich nickel phase, so nickel gathered in rich nickel phase and $\mathrm{Ni}_{3} \mathrm{Al}$ will come into being. That is $\mathrm{Ni}_{3} \mathrm{Al}+2 \mathrm{Al}=3 \mathrm{NiAl}$.

\section{Conclusions}

$\mathrm{Ni}-\mathrm{Al}$ system functionally gradient materials are successfully fabricated by the SHS. Compared with the conventional sintering, the laser sintering makes the specimens have the better properties. The fact that the properties such as the synthesized density and densification parameter of the laser sintered specimens are much better than those of conventionally sintered specimens indicates that SHS is a potential process for the FGMs.

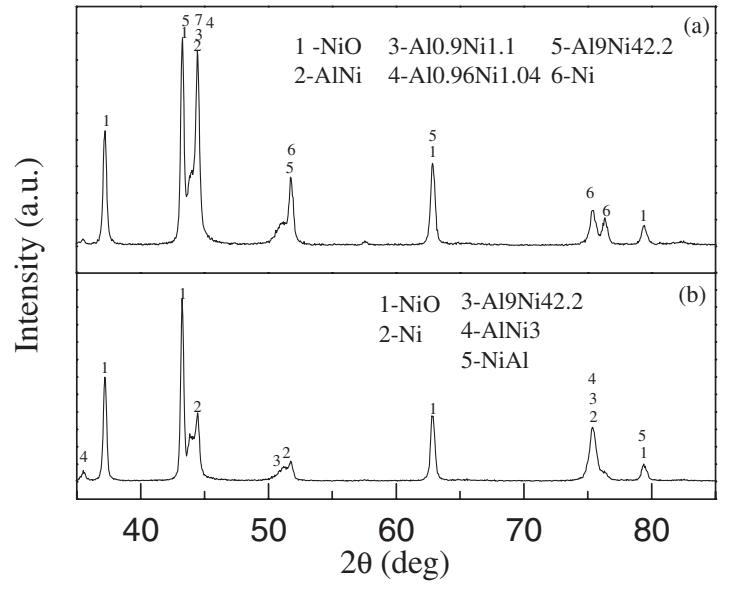

Fig. 6 XRD of the central ignition zone (a) and the fringe (b)

Because of high power density, ignition and reaction time are shortened, and the highest temperature which reaction can reach is improved. So the method of FGMs by laser selfpropagating high-temperature synthesis can simplify production procedures and get pure production. For lasersintered FGMs, it is important to produce FGMs that how to select the composition (the content of nickel and aluminium powders in every layer) and processing parameters such as laser power and green density.

The distribution of nickel and aluminium is smooth in laser-sintered FGMs. Experiments show that the green density is $70 \%$ of the theoretical density; we can get more compact materials. And FGMs with five or six layers are perfect. Top and bottom layers are nickel and aluminium respectively. We change the amount of gradient layers. When FGMs have seven layers and more, they have more holes. But if they have three and four layers, the FGMs are not integrated. So the FGMs with five or six layers are perfect.

\section{REFERENCES}

1) J. R. Jurado and Electrical: Journal of the European Ceramic Society. 20 (2000) 1611-1620.

2) H. Doty and R. Abbaschian: Mater. Sci. Eng. A. 195 (1995) 101-111.

3) J. D. Hu, Z. X. Guo, Q. F. Guan and Y. L. Li: Optics \& laser Technology. 29 (1997) 75-78.

4) Y. L. Li, Q. F. Guan and J. D. Hu: Chinese Science Bulletin. 42 (1997) 2014-2016.

5) P. Shen, Z. X. Guo and J. D. Hu: Scr. Mater. 43 (2000) 893-898.

6) K. Mohammed Jasim, R. D. Rawlings and D. R. F. West: J. Mater. Sci. 28 (1993) 2820-2826.

7) J. H. Abboud, D. R. F. West and R. D. Rawlings: J. Mater. Sci. 29 (1994) 3393-3398.

8) J. H. Abboud, D. R. F. West and R. D. Rawlings: Mater. Sci. Technol. 10 (1994) 848-853. 